\title{
Hermeneutic phenomenological research method simplified
}

- Narayan Prasad Kafle

This write-up aims to first clarify the notion of phenomenology by offering sayings of different experts of this genre. Thereafter, it attempts to briefly trace its genesis and classify this broad idea in three different schools viz. transcendental, hermeneutic and existential. After discussing very precisely on each of these schools, it focuses on the premises of hermeneutic phenomenology as a method for doing research. The purpose of this essay is to collect and exhibit a crude paradigmatic clue of doing a hermeneutic phenomenological research. During the course, it emphasizes on the metaphysical stance, methodological grounds, quality concerns and ethical issues that contribute to its paradigmatic assumptions.

\section{Defining phenomenology}

Phenomenology is an umbrella term encompassing both a philosophical movement and a range of research approaches. The phenomenological movement was initiated by Husserl (1859-1838) as a radically new way of doing philosophy. Later theorists, such as Heidegger (1889-1976), have recast the phenomenological project, moving away from a philosophical discipline which focuses on consciousness and essences of phenomena towards elaborating existential and hermeneutic (interpretive) dimensions (Finlay, 2009).

Finlay (2009) further states that applied to research, phenomenology is the study of phenomena: their nature and meanings. The focus is on the way things appear to us through experience or in our consciousness where the 
phenomenological researcher aims to provide a rich textured description of lived experience.

Langdridge (2007) defines phenomenology as a discipline that "aims to focus on people's perceptions of the world in which they live in and what it means to them; a focus on people's lived experience" (p.4). She further clarifies that phenomenology as a qualitative method focuses on human experience as a topic in its own right. It concerns with meaning and the way in which meaning arises in experience.

Phenomenology has been conceptualized as a philosophy, a research method and an overarching perspective from which all qualitative research is sourced (Maykut \& Morehouse, 1994). Merleau-Ponty (1962) in his famous book 'Phenomenology of Perception' has identified four qualities that are considered as 'celebrated themes' or characteristics common to different schools of phenomenology. These qualities are description, reduction, essences and intentionality.

According to Merleau-Ponty (1962) the aim of phenomenology is description of phenomena. Reduction is a process that involves suspending or bracketing the phenomena so that the 'things themselves' can be returned to. Likewise an essence is the core meaning of an individual's experience that makes it what it is. Finally, intentionality refers to consciousness since individuals are always conscious to something. This means intentionality is the total meaning of the object or the idea which is always more than what is given in the perception of a single perspective.

According to Berrios (1989) the term phenomenology refers to a set of philosophical doctrines loosely sharing; a) assumptions as to what the world is like (ontological) and how it can be known (epistemological) and b) strategies for the descriptive management of the mental entities relating to such a world. They all strive to capture experiential essences which are but 
higher forms of knowledge with which the phenomenologists expects to reconstruct reality on a firmer footing.

A more simplistic definition about phenomenology is offered by Grbich (2007) who states phenomenology as an approach to understand the hidden meanings and the essences of an experience together. Max van Manen (1990) another noted name who considers phenomenology as the appropriate most method to explore the phenomena of pedagogical significance elaborates phenomenology as a response to how one orients to lived experience and questions the way one experiences the world.

These definitions of phenomenology offered by different scholars focus that it is phenomenology that has the potential to penetrate deep to the human experience and trace the essence of a phenomenon and explicate it in its original form as experienced by the individuals. This quality of illumination of the core state of being of a phenomenon requires a very careful attention and the outcome is naturally greater than the sum of its parts.

\section{Genesis and schools of phenomenology}

The philosophy of phenomenology is not just a single approach idea. Though it formally began with Edmund Husserl (18591938) as a distinct and radical form of knowledge it roots to almost every religious thought available in the west and in the east as well as with different noted philosophers of different times.

So far as the tradition of western thought is concerned it was basically Desecrates who first floated the ideal of double existence of truth in the form of body and soul often discussed as the principle of dualism (Sikerry, 2006). Similar concept for the existence of two forms of reality can be traced in the writings of Immanuel Kant (1724-1804) who mentioned about phenomena standing for real and noumena meaning the 
problematic. In the writings of Georg Wilhelm Fredrick Hegel (1770-1831) we can find the existence of double forms of experiencing reality, which he mentions as absolute and realizable. Edmund Husserl, known as the father of phenomenology also mentions the truth to be either phenomenological meaning the real or natural which denotes for our everyday understanding of the phenomena. This western tradition about the existence of two forms of reality pauses with Martin Heidegger who mentions Dasein meaning 'beings of being' which is a remarkable departure from the existence of double truths towards one.

Similar development of understanding in terms of this ontological issue is observable even in the literatures of eastern origin. Though the basics for the difference in eastern and western mode of thinking lies in the primacy of 'being' in the west and primacy of 'ethics' in the east, the idea about the existence of different forms of truth is quite similar in the eastern tradition as well.

Hinduism considers Brahman meaning the infinite truth and Atman meaning the individual one. von Eckartsberg \& Valle (1981) in their famous writing 'Hiedeggerian Thinking and the Eastern Mind' make a very convincing comparison of phenomenology with the eastern notion of the highest form of consciousness where an individual remains unattached to any preoccupations and sets oneself free from all desires called 'liberation', Samadhi or Mokshya.

In the Buddhist scriptures there is the mentioning of Parmartha Satya meaning the real and Samvriti Satya meaning the individual or the practiced truth. Barendrest (1996) in his article 'Buddhist Phenomenology' mentions that Buddhism is for first lessening and in the end the elimination of human sufferings and this goal is to be reached by the path of experiential phenomenology that refers to the investigation of our consciousness as it is presented to us by means of self 
observation. In Buddhism it is the meditation that paves this path for Samyak (right) living.

According to Wilberg (2006), it is Advaita Vedanta in the east that marks a pause like Heidegger in the west that ultimately focuses on the 'principle of awareness' as the single route to all forms of reality. As clarified by Wilberg (2006) 'the awareness principle' is the sole possible theory of everything. It roots to the Non-dual or Advaita schools of Hindu philosophy which sets primacy of Chit (Awareness) over Sat (Being).

Relatively unexplored and less discussed in research discourse, the eastern notions of the principle of dualism and the consciousness display a very rich eastern tradition which even transcends the western ideology of phenomenology. This notion prevails in rich volumes in the Hindu, Buddhist and other scriptures of the east.

Nevertheless when we closely observe the western tradition of phenomenology we can distinctly classify the phenomenological tradition under three major headings. They are:

- Transcendental Phenomenology

- Hermeneutic Phenomenology

- Existential Phenomenology

Here follows a brief description about each of these schools.

\section{Transcendental phenomenology}

Transcendental phenomenology is the original form of phenomenological philosophy as conceptualized by Edmund Husserl (1859-1938). 'Logical Investigations' published by Husserl in 1900-1 proved to be a benchmark in the world of philosophy with this publication. Two other master pieces by Husserl named 'Formal and Transcendental Logic (1929) and Cartesian Meditations (1931) made phenomenology known to the whole world. The notion of phenomenology as envisaged by 
Husserl is termed later as transcendental phenomenology. The basic premise of this school of phenomenology its adherence to the notion that experience is to be transcended to discover reality. Husserlian phenomenology is built up round the idea of reduction that refers to suspending the personal prejudices and attempting to reach to the core or essence through a state of pure consciousness. Therefore, transcendental phenomenology advocates for applying the phenomenological attitude over natural attitude. The basic interest of this school of phenomenology is to discover and describe 'lived world'.

The research pattern based on this school of thought believes that it is possible to suspend personal opinion; it is possible to arrive to a single, essential and descriptive presentation of a phenomenon. Quite similar to that of the positivist tradition, the advocates of this branch of phenomenology think that if there is more than one reality that leaves doubt and lack of clarity. However there are debates on how to practice reduction. Bracketing and epoche are the terminologies that are associated with this process but about the integration of personal opinion during description are different from scholars to scholars.

\section{Hermeneutic phenomenology}

A sharp departure can be observed in the ideas floated by another school of phenomenology termed as hermeneutic phenomenology. It comes off the writings of Martin Heidegger (1889-1976), a disciple of Husserl. This departure is primarily because of the rejection of the idea of suspending personal opinions and the turn for the interpretive narration to the description. Based on the premises that reduction is impossible and acceptance of endless interpretations this school of phenomenology puts an effort to get beneath the subjective experience and find the genuine objective nature of the things as realized by an individual. Hermeneutic phenomenology is focused on subjective experience of individuals and groups. It is an attempt to unveil the world as experienced by the subject through their life world stories. This school believes that 
interpretations are all we have and description itself is an interpretive process. To generate the best ever interpretation of a phenomenon it proposes to use the hermeneutic cycle.

The publication of History of Concept of Time (1925) and Being and Time (1927) by Martin Heidegger paved the foundation to this school of thought. Later it was enriched by the scholars like Hans George Gadamar, Poul Ricour, and Max van Manen. The latter texts will detail the assumptions of hermeneutic phenomenology and finally draw a set of core elements related to research applying this school of thought.

\section{Existential phenomenology}

Existentialism was self-consciously adopted as a label for a movement only in the twentieth century. But existentialist writers see themselves as carrying on a tradition that was first anticipated by Blaise Pascal's (1623-62) rejection of Cartesian rationalism, which tried to define human being in terms of our rational capacities. Pascal saw human being as an essential paradox, a contradiction between mind and body. Soren Kierkegaard (1813-55), usually acknowledged as the founder of modern existentialism, shared Pascal's sense for the inherent contradiction built into the human condition. According to Warthal (2006), it is the name designated to the common to the thought of Heidegger (1889-1976), Jean Paul Sartre (19051980) and Maurice Merleau-Ponty (1908-1961) and other philosophers influenced by them. Though none of the scholars who contributed to this discipline preferred labeling them with 'existential phenomenologists' they did their projects in related ways. All the same, there is a justification for grouping these philosophers together under the heading "existential phenomenology." This justification is grounded in commonalities in their understanding of the phenomena upon which they focus, and in the phenomenological method they use to account for such phenomena. 
Existential phenomenologists all share the view that philosophy should not be conducted from a detached, objective, disinterested, disengaged standpoint. This is because, they contend, certain phenomena only show themselves to one who is engaged with the world in the right kind of way (Warthal, 2006). Existential phenomenologists have included descriptions of the meaning of being (Heidegger), the role of the lived-body in perception (Merleau-Ponty).

The ground that keeps it distinct to other schools of phenomenology is its rejection of Husserl's belief of possibility of complete reduction and its firm belief on the attempt to concentrate upon re-achieving a direct and primitive contact with the world. For this, existential phenomenology stresses on the description of everyday experience as it is perceived by the consciousness of the individuals.

\section{Hermeneutic phenomenological research}

The tradition of phenomenological research is found in the philosophical literature. The key figures exemplifying the synthesis that is hermeneutic phenomenology are Martin Heidegger, Hans-Georg Gadamer and Paul Ricoeur (Thompson, 1981, p. 36). The phenomenological research tradition requires the researcher to acquire the essence of the research process as this is opened up in the philosophical literature. In the practice of engaging in phenomenological research, the researcher is required to seek the essence of the tradition belonging to the phenomenological way, while also attuning his/her being towards the essence of a particular phenomenon.

Phenomenological research is a lived experience for researchers as they attune themselves towards the ontological nature of phenomenon while learning to "see" pre-reflective, taken-forgranted, and essential understandings through the lens of their always already pre- understandings and prejudices (van Manen, 1990). Heidegger (1996) declared that what is essential to our understanding withdraws from our rational grasp for control 
and certainty. As the phenomenological researcher remains towards that which withdraws from us, we are likened to a signpost pointing to the withdrawing (Heidegger, 1996). In phenomenological research, the researcher is a signpost pointing towards essential understanding of the research approach as well as essential understandings of the particular phenomenon of interest.

Phenomenology is a way of researching the essence or essential meanings of phenomena. Simply, phenomenology is "the study of essences" (Merleau-Ponty, 1962, p. vii). The term essence refers to the essential meanings of a phenomenon; that which makes a thing what it is (van Manen, 1990). Heidegger (1977) describes the essence of a phenomenon as "the way in which it remains through time as what it is" (p. 3). van Manen (1990) suggests that

A good [phenomenological] description that constitutes the essence of something is construed so that the structure of a lived experience is revealed to us in such a fashion that we are now able to grasp the nature and significance of this experience in a hitherto unseen way. (p. 39)

The researcher's understanding of an essence is always "on-theway", partial, and particular to the experiences from which the interpretations were formed. There is the possibility, in phenomenological research that new meanings emerge about a phenomenon that draws "something forgotten into visibility" (Harman, 2007, p. 92). The challenge of phenomenology is to describe what is given to us in immediate experience without being "obstructed by pre-conceptions and theoretical notions" (van Manen, 1990, p. 184). In a similar way, phenomenological research makes a distinction between appearance and essence, between the things within our experience and what grounds the things within our experience (Ehrich, 1999; van Manen, 1990). 
van Manen's $(1990,1997)$ take on hermeneutic phenomenology is very comprehensive and covers a wide range of practices under its umbrella with a typical focus to the concerns of pedagogical worth in a typical phenomenological writing pattern which demands for a writing to serve pedagogy that can even illuminate the silences. In order to devise the phenomenological writing he emphasizes on the use of anecdotal narrative with a creation of hybrid text to provide justice to the life world stories of the research participants. A distinction needs to be made between philosophical concerns and the engaged issues one faces as one actually goes to 'do' the research. For example, van Manen (1996) distinguished between phenomenology as a branch of philosophy and 'engaged phenomenology' as a social science endeavor. Those wishing to do an engaged phenomenological research are advised by Van Manen to read good phenomenological texts so that they can see what perceptive phenomenological material looks like. There is little chance that researchers will be able to engage in phenomenological research if they don't know what it looks or feels like.

A similar notion like that of van Manen about hermeneutic phenomenological research is exhibited by Evans (1999) in his book 'the pedagogic principal' where he uncovers the life world stories of schools principals and pitches that against their supposed instructional roles. Evans too stresses on the need of idiomatic expressions that can express the sentiments and intentions that are difficult if not impossible to be represented by everyday language.

Cohen (2001) states that 'hermeneutic phenomenology' is concerned with understanding texts. In this approach the researcher aims to create rich and deep account of a phenomenon through intuition, while focusing on uncovering rather than accuracy, and amplification with avoidance of prior knowledge. In using this approach we accept the difficulty of bracketing. To overcome this difficulty we acknowledge our implicit assumptions and attempt to make them explicit. In 
addition, we accept the notion that there may be many possible perspectives on a phenomenon, like when we turn a prism, one part becomes hidden and another part opens. Hermeneutic avoids method for method's sake and does not have a step by step method or analytic requirements. The only guidelines are the recommendation for a dynamic interplay among six research activities: commitment to an abiding concern, oriented stance toward the question, investigating the experience as it is lived, describing the phenomenon through writing and rewriting, and consideration of parts and whole.

Hermeneutic phenomenology is concerned with the life world or human experience as it is lived. The focus is toward illuminating details and seemingly trivial aspects within experience that may be taken for granted in our lives, with a goal of creating meaning and achieving a sense of understanding (Wilson \& Hutchinson, 1991).

Hermeneutic phenomenology is attentive to the philosophies underpinning both hermeneutics and phenomenology (van Manen, 1990). It is a "research methodology aimed at producing rich textual descriptions of the experiencing of selected phenomena in the life world of individuals that are able to connect with the experience of all of us collectively" (Smith, 1997, p. 80). From identification of the experience of phenomena, a deeper understanding of the meaning of that experience is sought (Smith, 1997). This occurs through increasingly deeper and layered reflection by the use of rich descriptive language.

According to Langdridge (2007), the hermeneutic turn of phenomenology resulted of the opinions that our experiences can be best understood through stories we tell of that experience. To understand the life world we need to explore the stories people tell of their experiences, often with the help of some specific hermeneutic or method of interpretation. 
Laverty (2003) in his article makes a clear distinction between phenomenology and hermeneutic phenomenology and their historical and methodological considerations. According to him, hermeneutic phenomenology differs with phenomenology in terms of ontological, epistemological and methodological grounds. Taking self reflection as the standpoint for Laverty data is to be interpreted using hermeneutic circle that consists of reading, reflective writing and interpretation.

Groenwald (2004) in his article 'A Phenomenological Research Design Illustrated' mentions some structured patters of doing a hermeneutic phenomenological research. Beginning with locating the research participants, data collection techniques, data storing methods, data explication strategies and validating $\&$ truthfulness, he proposes for a systematic steps for doing phenomenological research. Similar structured pattern is proposed by Aspers (2004) who has outlined a seven step process consisting of first order and second order constructs.

According to Sharkey (2001) hermeneutic phenomenology challenges the researcher to reflect deeply on what it is that the texts of the field have to say. The researcher is called to play with the texts - to get lost in deep conversation with them. The goal of this type of research is not to clone the texts of the field for the reader of the research but to invite the reader to enter the world that the texts would disclose and open up in front of themselves.

\section{Hermeneutic phenomenological research paradigm}

On the grounds of above discussions about phenomenology as a philosophy, different schools of phenomenology and some prescriptive and structured methods of doing a hermeneutic phenomenology in particular, a hermeneutic phenomenological research paradigm with its key ingredients have been proposed below. This paradigmatic concern of doing a phenomenological (hermeneutic) research is drawn not from a single author but it is based on ideas floated by different scholars at different times. 
Michel Foucault and Thomas Kuhn appear to be the two prominent figures in the 20th century that caused an ever-since increasing attention to the word 'paradigm'. According to Kuhn there are two essential qualities of a paradigm:

First the paradigm must be "sufficiently unprecedented to attract an enduring group away from competing modes of scientific activity" and second "sufficiently open-ended to leave all sorts of problems for the redefined group of practitioners to resolve" (Kuhn 1962, p.10).

In literal sense a paradigm can be perceived as a loose collection of logically related assumptions, concepts or propositions that orient thinking and research. While applied to the tradition of a qualitative research a paradigm consists of four major components. They are:
a) Metaphysics
b) Methodology
c) Quality, and
d) Ethics.

The metaphysics of a research is constituted of ontology, epistemology and axiology. These considerations determine how a researcher undertakes his/her activities. In reference to the metaphysical ground of a researcher Greenbank (2003) argues:

When researchers are deciding what research methods to adopt they will inevitably be influenced by their underlying ontological and epistemological position. This in turn will be influenced by their values ... (p.92).

Ontology is concerned with reality. It is the science of study of being. The reality can be external to individuals or produced by individual consciousness (Cohen et al., 2000). While applied to hermeneutical phenomenological research reality is perceived as an individual construct dependent to different situations. Hereafter, it is rested on the belief that realities are multiple. 
Epistemology is concerned with 'how we know what we know'. It refers knowledge and the notion that the research work is supposed to make contribution to knowledge itself. According to Hartley (2006) epistemology is the process through which the researcher makes the knowledge claim. Hermeneutic phenomenological research is rested on the ground of the subjective knowledge. As a philosophy of knowledge applied in hermeneutic phenomenology the epistemology is grounded on the belief that knowledge making is possible through subjective experience and insights.

Ontology and epistemology deal with truth however axiology is about values and ethics (Mingers, 2003). Axiology is also called value theory, and includes the disciplines of ethics, pragmatics and aesthetics. Values provide the standard for the evaluation of epistemological and ontological claims. In reference to research literature, axiology also refers to the involvement of the researcher's values and opinion in the process of knowledge generation. In this connection the hermeneutic phenomenology aligns with the idea of practical form of knowledge generation that goes beyond the enumeration of mathematical properties.

Though there is no prescription about the unanimous methodological sets of doing a hermeneutic phenomenological research, on the light of different researches conducted using this paradigm we can suggest for few methodological guidelines. The noted scholars of this disciplines like van Manen (1990, 1997), suggest that there is no fixed set of methods to conduct this type of research. But as a variant of qualitative research the purposive sampling with information rich cases is suggested by Merriam (1998). For data generation, multiple tools can be utilized that include interview, observation, and protocols. Since the purpose is to generate the life world stories the research participants, depending the context and the area of research the appropriate tool can be applied. Data is recommended to be processed uncovering the thematic aspects by van Manen (1997). Data analysis is often 
performed applying the hermeneutic cycle that constitutes of reading, reflective writing and interpretation in a rigorous fashion (Laverty, 2003). This process can be demonstrated as in the given figure.

Figure: 1 Hermeneutic Cycle

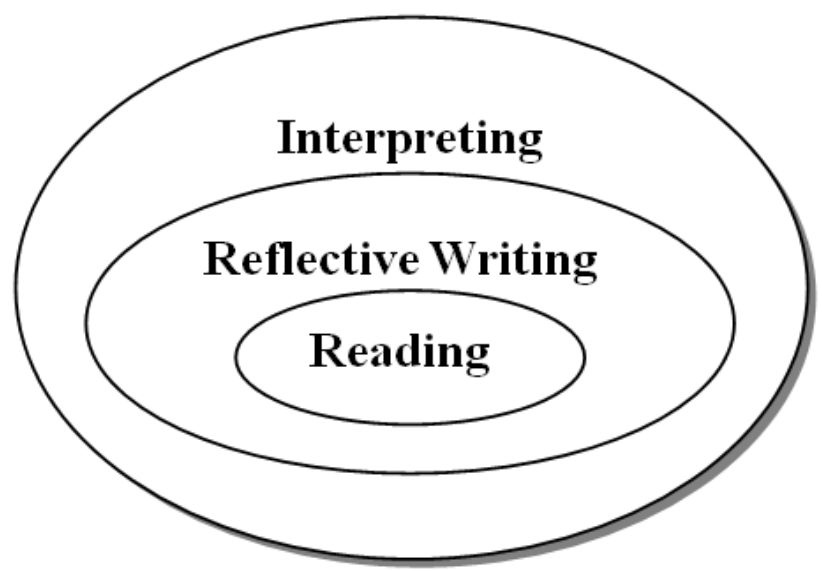

Maintaining the quality of the entire research process and the product is the most crucial aspect of hermeneutic phenomenological research. In terms of quality issue there are contesting opinions about the quality claims of this type of research. In judging the trustworthiness of qualitative research, Guba and Lincoln (1999) have identified four standards: credibility, transferability, dependability and conformability. But all these quality claims may not fit appropriate with hermeneutic phenomenology. van Manen (1997) who associates hermeneutic phenomenology as a paradigm appropriate to the research having pedagogic significance has enlisted four rigor criteria for this type of research. Considering hermeneutic phenomenology as a pedagogic practice of textuality where doing research is to be involved in the considering of the texts that explicate the life world stories of the research participants, van Manen (1997) enlists orientation, strength, richness and depth as the major quality concerns. 
According to him, orientation is the involvement of the researcher in the world of the research participants and their stories. Strength refers to the convincing capacity of the text to represent the core intention of the understanding of the inherent meanings as expressed by the research participants through their stories. Richness is intended to serve the aesthetic quality of the text that narrates the meanings as perceived by the participants. Depth is the ability of the research text to penetrate down and express the best of the intentions of the participants. Likewise, Langdridge (2007) proposes for analytical rigor, persuasive account, and participant feedback as the major components that determine the quality of a hermeneutic phenomenological research. Analytical rigor refers to the attitude displayed by the researcher to pay attention to every case that either confirms or disconfirms the theme. No taken for granted attitude is permitted during the hermeneutic analysis. Persuasive account refers to the quality of convincing the reader and its appeal to think about the personal experience for the reader on the light of what he/she has read. Participant feedback is another quality trail that a hermeneutic phenomenological research has to pass before reaching to its audience since it helps to best represent what is intended by the participants.

To make all these quality claims what is most important with hermeneutic phenomenological research is to pay attention to the rhetoric. Rhetoric refers to the writing or reporting style of the research work. According to Firestone (1987) rhetoric is the art of speaking and writing effectively. It refers generally to how language is employed. Since hermeneutic phenomenology aims at explicating the core essences as experienced by the participants, the everyday language can not do justice to express what is intended by the participants. That is why hermeneutic phenomenology demands for a typical rhetoric that best elicit the true intention of the research participants. A language mode with informal tone with idiographic expressions full of adages and maxims is considered suitable for reporting this type of research. 
Ethical issues are equally important in hermeneutic phenomenology like any other research paradigms. As a qualitative research paradigm, some ethical issues must be observed and practiced while doing this kind of researching. Along with the ethical standards for qualitative research proposed by Creswell (2007) who mentions assigning aliases to the participants to protect their privacy, clarifying the purpose and procedure of the research beforehand, obtaining informed consent and not disclosing the identities of participants and places a number of other ethical practices are to be applied that include the strict adherence to the ethics or care, confidentiality and other issues as required like that of sharing the research findings with the participants.

The research paradigm drawn here is just a tentative guideline for carrying out a hermeneutic phenomenological research and is not meant for limiting its outstanding broadness it constitutes of. It is the outcome of the title justification 'Hermeneutic Research Method Simplified'.

\section{Conclusion}

Phenomenology as a school of philosophy has a wide spread recognition and it has definitely influenced the way we think of a phenomenon. A discipline of European origin, phenomenology, has received a global identity and remains one of the most sought after as well as debated topic of interest over the century. It is applied in almost all disciplines including medical science, education and even in science and technology. Unlike other qualitative research designs, it has relatively remained free from the criticisms due to its philosophical and methodological strengths. Hermeneutic phenomenology by its very name is an interdisciplinary approach that takes from across the disciplines and has a very convincing yet distinct set of principles that are essentially targeted to uncovering the better understanding of a phenomenon. As a method within the interpretive research paradigm, it shares quite a many similarities with other research designs yet it has its own 
premises and differs from many of them on different footings. To do a hermeneutic phenomenological research is an engaging process where the orientation towards the phenomenon is the matter of central concern and its reporting rhetoric demands for a unique richness.

\section{References}

Aspers, P. (2004). Empirical phenomenology: An approach for qualitative research. Papers in Social Research Methods, Qualitative Series 9. London: London School of Economics and Political Science Methodology Institute.

Barendregt, H. P. (1996). Mysticism and beyond, Buddhist phenomenology part II. The Eastern Buddhist, New Series, XXIX, 262-287.

Berrios, G. E. (1989, July). What is phenomenology? A review. Journal of the Royal Society of Medicine, 82, 425-428.

Cohen, A. (2001). Review of literature: Responses to "Empirical and hermeneutic approaches to phenomenological research in psychology, a comparison". Gestalt, 5(2). Retrieved from http://www.g-gej.org/5-2/reviewlit.html

Cohen, L., Manion, L., \& Morrison, K. (2000). Research methods in education (5th ed.). London: Routledge Falmer.

Creswell, J. (2007). Qualitative inquiry \& research design: Choosing among five approaches (2nd ed.). Thousand Oaks, CA: Sage.

Ehrich, L. C. (1999). Untangling the threads and coils of the web of phenomenology. Education Research and Perspectives, 26(2), 19-44.

Evans, R. (1999). The pedagogic principal. Canada: Qualitative Institute Press.

Finlay, L. (2009). Debating phenomenological research. Phenomenology \& Practice, 3(1), 6-25.

Firestone, W. A. (1987). Meaning in methods: The rhetoric of quantitative and qualitative research. Educational Researcher, 16(7), 16-21.

Grbich, C. (2007). Qualitative data analysis: An introduction. London: Sage Publications Inc. 
Greenbank, P. (2003). The role of values in educational research: The case for reflexivity. British Educational Research Journal, 29(6), 791-801.

Groenwald, T. (2004). A phenomenological research design illustrated. International Journal of Qualitative Methods, $3(1), 1-26$.

Guba, E. G., \& Lincoln, Y. S. (1999). Naturalistic and rationalistic enquiry. In J. P. Keeves \& G. L. Lafomski (Eds.), Issues in educational research (pp. 141-149). New York: Pergamon.

Harman, G. (2007). Heidegger explained: From phenomenon to thing. Illinois: Open Court.

Hartley, D. (2006) Pulling us apart? Relativism and instrumentalism in contemporary educational research. Educational Review, 58(3), 269-272.

Heidegger, M. (1977). The question concerning technology and other essays (W. Lovitt, Trans.). New York: Harper.

Heidegger, M. (1996). Being and time: A translation of Sein and Zeit (J. Stambaugh, Trans.). Albany, New York: State University of New York Press.

Kuhn, T. (1962). The structure of scientific revolutions. Chicago: University of Chicago Press.

Langdridge, D. (2007). Phenomenological psychology: Theory, research and methods. London: Pearson.

Laverty, S. M. (2003). Hermeneutic phenomenology and phenomenology: A comparison of historical and methodological considerations. International Journal of Qualitative Methods, 2(3), 21-35.

Maykut, P. M., \& Morehouse, R. (1994). Beginning qualitative research: A philosophic and practical guide. London: The Falmer Press.

Merleau-Ponty, M. (1962). Phenomenology of perception. London: Routledge \& Kegan Paul.

Merriam, S. B. (1998). Qualitative research and case study applications in education. San Francisco, CA: JosseyBass.

Mingers, J. (2003). A classification of philosophical assumptions of management science methods. Journal of the Operational Research Society, 54, 559-570. 
Review of Descartes: An intellectual biography and Descartes' error: Emotion, reason, and the human brain. Retrieved from http://www.123HelpMe.com/view.asp?id=160418

Sharkey, P. (2001). Hermeneutic phenomenology. In R. Barnacle (Ed.), Phenomenology (pp. 16-37). Melbourne: RMIT Publications.

Skirry, J. (2006). Rene Descartes: The mind-body distinction. Retrieved from http://www.iep.utm.edu/descmind/

Smith, S. J. (1997). The phenomenology of educating physically. In D. Vandenburg (Ed.), Phenomenology and educational discourse (pp. 119-144). Durban: Heinemann.

Thompson, J. (1981). Critical hermeneutics: A study in the thought of Paul Ricoeur and Jürgen Habermas. Cambridge: Cambridge University Press.

van Manen, M. (1996). Method and meaning in the human sciences. Paper presented in a Conference at Newcastle University, England.

van Manen, M. (1997). Researching lived experience: Human science for an action sensitive pedagogy (2nd ed.). Canada: The Althouse Press.

von Eckartsberg, R., \& Valle, R. S. (1981). Heideggerian thinking and the eastern mind. In R. S. Valle \& R. von Eckartsberg (Eds.), Metaphors of consciousness (pp. 287-311). New York and London: Plenum Press.

Warthhall, M. A. (2006). Existential phenomenology. In H. L. Dreyfus, \& Wrathall, M. A. (Eds.), A companion to phenomenology and existentialism (pp. 229-239). Oxford: Blackwell Publishing Ltd.

Wilberg, P. (2006). The awareness principle, Advaita and European phenomenology. Retrieved from http://www.thenewyoga.org/advaita.htm

Wilson, H., \& Hutchinson, S. (1991). Triangulation of qualitative methods: Heideggerian hermeneutics and grounded theory. Qualitative Health Research, 1, 263-276.

The author is a PhD scholar at School of Education, Kathmandu University. 